\title{
Quiste de la bifurcación bucal mandibular. Análisis sistemático de la literatura y
}

\section{reporte de un caso}

\author{
Mandibular buccal bifurcation cyst. Systematic analysis of the literature and a case report \\ Cisto da bifurcação oral mandibular. Análise sistemática da literatura e relato de um caso
}

Recibido: 19/04/2021 | Revisado: 23/04/2021 | Acepto: 24/04/2021 | Publicado: 09/05/2021

\author{
Marcelo Enrique Cazar Almache \\ ORCID: https://orcid.org/0000-0002-6806-7442 \\ Universidad de Cuenca, Ecuador \\ E-mail: marcelo.cazar@ucuenca.edu.ec \\ María Fernanda Torres Calle \\ ORCID: https://orcid.org/0000-0002-8097-212X \\ Universidad de Cuenca, Ecuador \\ E-mail: mfernanda.torresc@ucuenca.edu.ec \\ Jonnathan Xavier López Tumbaco \\ ORCID: https://orcid.org/0000-0001-7718-9671 \\ Universidad de Cuenca, Ecuador \\ E-mail: jonnathan.lopez@ucuenca.edu.ec \\ Paul Andrés Torres Cevallos \\ ORCID: https://orcid.org/0000-0001-7144-1776 \\ Universidad de Cuenca, Ecuador \\ E-mail: paul.torres@ucuenca.edu.ec
}

\begin{abstract}
Resumen
Introducción: El quiste de la bifurcación bucal mandibular (QBBM) es una lesión quística de origen odontogénico, que se presenta en relación con la superficie bucal del primer y segundo molar mandibular, con características clínicas, radiográficas e histológicas similares a otras entidades patológicas de la mandíbula relacionadas a procesos inflamatorios. Clínicamente suelen presentarse como una inflamación en el vestíbulo de la región de primeros y segundos molares vitales, con presencia de bolsas periodontales profundas. Existe controversia en la etiología exacta y el tratamiento por lo que el presente estudio tiene como objetivo discutir las características clínicas y radiográficas del QBBM, el diagnóstico diferencial y su tratamiento el cual difiere si la enucleación quística incluye o no la extracción dental. Metodología: Se realizó una revisión sistemática de la literatura en distintas bases digitales, recopilando información relevante que justifique los hallazgos del presente caso. Resultados: En este caso en particular ciertas características como la proyección del esmalte en la zona de la bifurcación fue un indicativo claro del QBBM. El tratamiento de elección fue la enucleación del quiste con la extracción de la pieza dentaria.

Palabras clave: Quiste paradental; Quiste de la bifurcación bucal; Quiste paradental inflamatorio.
\end{abstract}

\begin{abstract}
Introduction: The mandibular buccal bifurcation cyst (MBBC) is a cystic lesion of odontogenic origin, which occurs in relation to the buccal surface of the first and second mandibular molars, with clinical, radiographic and histological characteristics similar to other pathological entities of the mandible related to inflammatory processes. Clinically, they usually present as an inflammation in the vestibule of the vital first and second molar region, with the presence of deep periodontal pockets. There is controversy regarding the exact etiology and treatment, so the present study aims to discuss the clinical and radiographic characteristics of QBBM, the differential diagnosis and its treatment, which differs whether or not cystic enucleation includes tooth extraction. Methodology: A systematic review of the literature was carried out in different digital databases, collecting relevant information that justifies the findings of this case. Results: In this particular case, certain characteristics such as enamel projection in the bifurcation area was a clear indication of MBBC. The treatment of choice was the enucleation of the cyst with the extraction of the tooth.
\end{abstract}

Keywords: Paradental cyst; Buccal bifurcation cyst; Inflammatory paradental cyst.

\section{Resumo}

Introdução; O cisto de bifurcação bucal mandibular (CBBM) é uma lesão cística de origem odontogênica, que ocorre em relação à superfície vestibular do primeiro e segundo molares inferiores, com características clínicas, radiográficas e histológicas semelhantes a outras entidades patológicas da mandíbula relacionadas a processos inflamatórios. Clinicamente, apresentam-se na maioria das vezes como uma inflamação no vestíbulo da região do primeiro e segundo molar, com presença de bolsas periodontais profundas. Há controvérsias quanto à exata etiologia e tratamento, portanto o presente estudo tem como objetivo discutir as características clínicas e radiográficas da QBBM, 
o diagnóstico diferencial e seu tratamento, que difere se a enucleação cística inclui ou não extração dentária. Metodologia: Foi realizada uma revisão sistemática da literatura em diferentes bases de dados digitais, recolhendo informações relevantes que justificam os achados deste caso. Resultados: Neste caso particular, certas características como a projeção do esmalte na área de bifurcação foi uma indicação clara de CBBM. O tratamento de escolha foi a enucleação do cisto com extração do dente.

Palavras-chave: Cisto paradental; Cisto de bifurcação bucal; Cisto paradental inflamatório.

\section{Introducción}

El quiste de la bifurcación bucal mandibular, también conocido como quiste bucal mandibular infectado o quiste paradental juvenil (Quintanilla, Amigo, Quintanilla, \& Hidalgo, 2018). Es una lesión quística odontogénica inflamatoria poco común que está asociada al primer o segundo molar mandibular en pacientes jóvenes. La primera descripción la hizo Hofrath (1930) quien reportó varios casos de quistes situados en distal del tercer molar mandibular con pericoronitis.

Main (1970) utiliza el término quiste periodontal inflamatorio para distinguirlo de un quiste radicular asociado a un canal accesorio lateral de un diente no vital y de un quiste periodontal del desarrollo. Craig (1976) describe detalladamente la lesión y sugirió que el término "quiste paradental” era apropiado por presentarse en la cara lateral de las raíces de terceros molares mandibulares con antecedente de pericoronitis.

Por su localización específica Stoneman y Worth (1983) lo llaman "quiste bucal mandibular infectado" siendo los primeros en documentar las características clínicas y radiográficas en la superficie bucal del primer o segundo molar inferior. La Organización Mundial de la Salud (1992) ha incluido esta lesión en la categoría de "quiste paradental" y sugiere el término "quiste bucal mandibular infectado". Pompura, Sandor y Stoneman (1997), han abogado por llamarlo "quiste de la bifurcación bucal mandibular" (QBBM) por su sitio específico.

La etiología es incierta y aunque se han planteado algunas hipótesis, se especula que se debe a una respuesta inflamatoria en el folículo del diente o por la formación de una bolsa vestibular (Neville, Damm, Allen, \& Chi, 2015). Algunos autores creen que el epitelio reducido del esmalte y los restos de Malassez en respuesta a estímulos inflamatorios pueden proliferar, sin embargo, Ackerman, Cohen y Altini (1987) citado por Chrcanovic (2011), argumentaron que si los restos de Malassez fueran los responsables de este desarrollo entonces los QBBM se distribuirían por toda la superficie radicular. Otras hipótesis incluyen un origen a partir de los restos epiteliales de la lámina dental (Philipsen, Reichart, Ogawa, Suei, \& Takata, 2004).

La presencia de una pequeña proyección de esmalte dentro de la zona de la bifurcación radicular sobre la cara vestibular de los molares ha sido mencionada por varios autores como factor predisponente (Craig \& GT, 1976) (Ackermann, Cohen, \& Altini, 1987) (Shear \& Speight, 2008) (Neville, Damm, Allen, \& Chi, 2015). Esta proyección puede facilitar la acumulación de placa bacteriana seguida de proliferación reactiva del periostio y destrucción ósea, con retención continua de restos alimenticios y bacterias en el surco dando como resultado una bolsa inflamatoria grande y profunda, o el desarrollo de un quiste paradental que con el tiempo se extiende hacia la furca radicular o más allá de ésta (Craig \& GT, 1976). El diagnóstico diferencial de esta lesión incluye al absceso periodontal, granuloma eosinofílico y quiste dentígero (Zadik, Yitschaky, Neuman, \& Nitzan, 2011).

El QBBM tiene características clínicas y radiográficas específicas. En la serie de Craig (1976) de 49 casos que representan el 5\% de 1051 quistes odontogénicos en un período de 21 años, casi dos tercios de los casos se produjeron en pacientes de la tercera década de edad. Clínicamente están asociados a primeros y segundos molares vitales, con presencia de bolsas periodontales profundas, puede estar alterado el patrón de erupción con inclinación bucal de la corona e inflamación del epitelio pericoronal (Pompura, Sándor, \& Stoneman, 1997) (Zadik, Yitschaky, Neuman, \& Nitzan, 2011). Los hallazgos radiográficos son una lesión radiolúcida en forma de U en la superficie vestibular del molar afectando las raíces con extensión variable, la corona se encuentra inclinada hacia bucal de tal manera que las raíces están desplazadas hacia la cortical lingual a 
expensas de la lesión, no se reporta en la literatura perforación de las corticales, pero es común evidenciar una reacción perióstica vestibular de forma simple o multilocular según la aposición de hueso nuevo en forma de una o varias capas (Bautista, y otros, 2019) (Philipsen, Reichart, Ogawa, Suei, \& Takata, 2004) (Pompura, Sándor, \& Stoneman, 1997).

Las características histológicas no son específicas y muestran un quiste que está delineado por un epitelio escamoso estratificado no queratinizado con áreas de hiperplasia. Abundante infiltrado inflamatorio crónico se encuentra presente en la matriz de tejido conjuntivo (Neville, Damm, Allen, \& Chi, 2015).

El objetivo de este trabajo es el reportar el caso clínico de una paciente femenina con el diagnostico de Quiste de la bifurcación bucal mandibular con perforación de corticales vestibular y lingual, tratado con enucleación e injerto óseo liofilizado para apoyo en investigaciones futuras.

\section{Metodología}

El presente estudio tiene un diseño no experimental, de tipo transversal con un alcance descriptivo. Cuenta con un enfoque metodológico cualitativo desarrollado a través de un estudio de caso (Hernández, Fernández, \& Baptista, 2014).

En un primer momento se realizó una revisión sistemática de documentos científicos relacionados con el área de la salud oral y patologías estomatológicas, específicamente sobre el QBBM. Para ello se llevó a cabo una búsqueda en bases digitales como Pubmed, Science Direct, Cochrane y Google Scholar. Esta búsqueda se realizó tanto en español como en ingles utilizando las palabras claves: Quiste de bifurcación mandibular, quiste bucal mandibular infectado, quiste paradental inflamatorio. No se presentó un intervalo en cuanto a los años de publicación y en la búsqueda se incluyeron revisiones sistemáticas, reportes de caso y libros de patología oral.

Tras la búsqueda inicial se recopilaron 115 artículos científicos. Finalmente se obtuvieron 22 fuentes bibliográficas en inglés y español que fueron analizadas en relación a las características clínicas e histopatológicas, pudiendo determinar los distintos hallazgos que se presentan en el reporte de caso. La paciente autorizó previamente, a través del consentimiento informado, la realización del tratamiento, documentación y la subsecuente publicación del mismo.

\section{Presentación del Caso}

Se presenta a la clínica de Cirugía Maxilofacial del Hospital Universitario del Rio, de la ciudad de Cuenca Ecuador, una paciente femenina de 20 años de edad con aumento de volumen de la región mandibular izquierda, sin datos de dolor, con una evolución de aproximadamente 3 meses, refiere un aumento de volumen lento y progresivo de dicha región durante ese período, por lo que acudió a un odontólogo de practica general, quien prescribe analgésicos y antibioticoterapia no especificada mostrando ligera remisión del aumento de volumen, por lo que es remitida a nuestra clínica para valoración.

A la exploración física presentó moderado aumento de volumen intra y extraoral de la región mandibular izquierda, con ligero dolor a la palpación, a la percusión del primer y segundo molar inferior izquierdo presenta disestesia, al sondaje se evidencia bolsa periodontal y movilidad grado III. Se realiza punción aspiratoria de contenido líquido de color amarillento, no fétido, con resultado citológico de infiltrado inflamatorio crónico inespecífico.

En el diagnóstico por imágenes de la radiografía panorámica (Figura 1) A nivel de cuadrante mandibular izquierdo en zona referente a segundo premolar inferior izquierdo a tercer molar inferior izquierdo, se determina la presencia de una imagen radiolúcida multilocular de bordes parcialmente corticalizados, que se extiende desde mesial del O.D. 3.5 hasta mesial del O.D. 3.8 (FDI World Dental Federation Notation). Presentando destrucción de la tabla óssea vestibular y esclerosis ósea reaccional periférica. Se determina rarefacción a nivel de furcación de O.D. 3.6 que ocasiona la pérdida de lámina dura, preservación del espacio de ligamento periodontal a nivel mesial de O.D. 3.5 y distal de O.D. 3.7 y ausencia del mismo a nivel mesial y distal 
de la pieza 3.6. Se observa desplazamiento del canal del conducto dentario inferior hacia el reborde mandibular y se determina la basal mandibular intacta.

Figura 1. Imagen radiolúcida multilocular a nivel de O.D. 3.5, 3.6, 3.7 y 3.8.

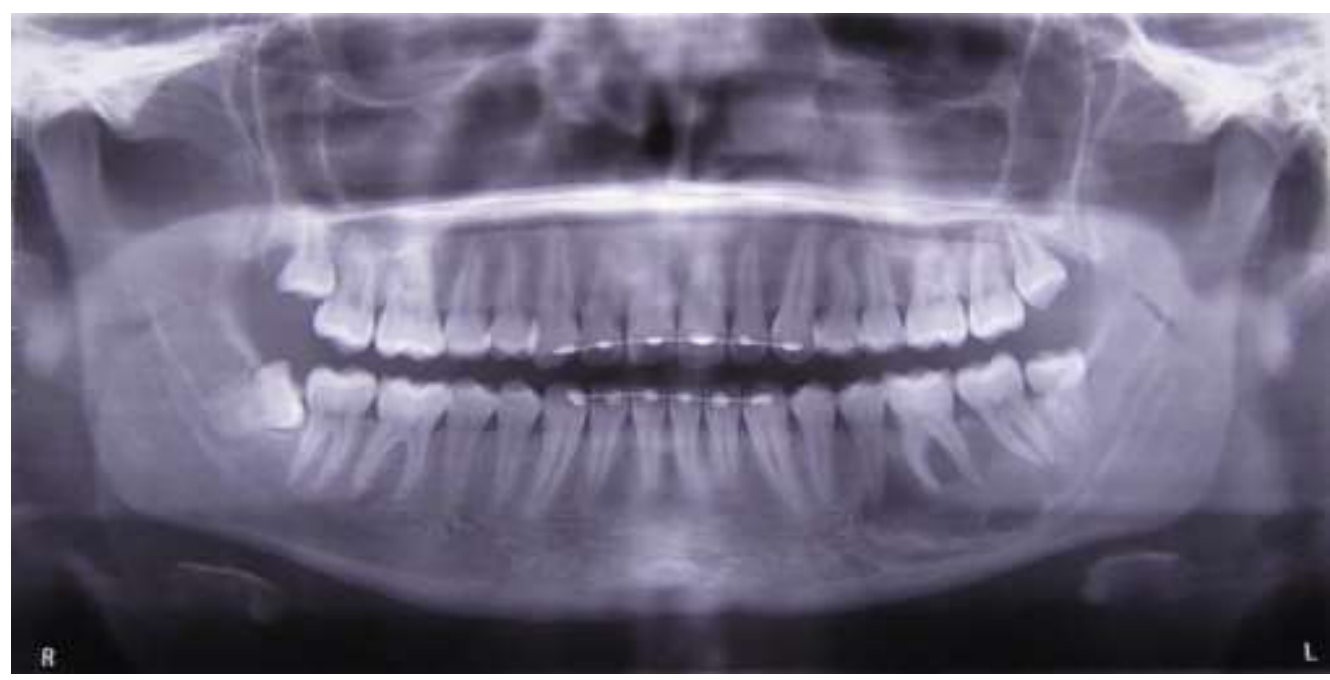

Fuente: Autores (2021).

En el análisis de la tomografía computarizada con reconstrucción 3D presenta la gran ventaja de que nos permite observar este tipo de lesiones en los tres planos del espacio (axial, coronal y sagital), con dosis de radiación muy bajas. Se determina abombamiento de tablas Oseas con perforación cortical vestibular en relación al O.D. 3.5 y 3.6 (Figura 2), y a nivel lingual se observa perforación cortical con exposición radicular a nivel de O.D. 3.7- 3.6 (Figura 3).

Figura 2. TC. con reconstrucción 3D. Se observa perforación en cortical vestibular.

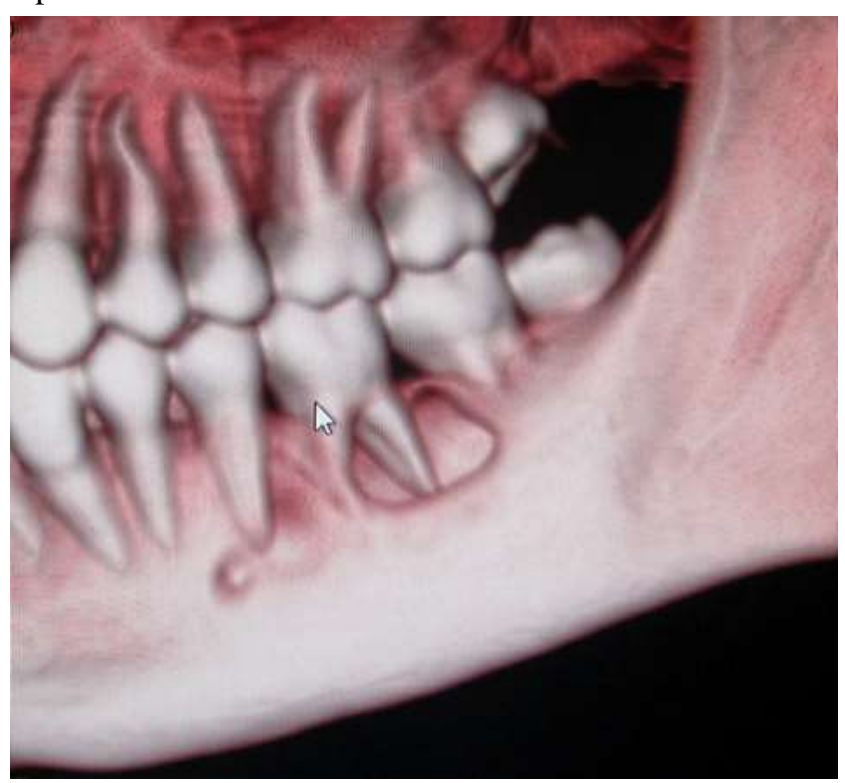

Fuente: Autores (2021).
Figura 3. TC. con reconstrucción 3D. Se observa perforación en cortical lingual.

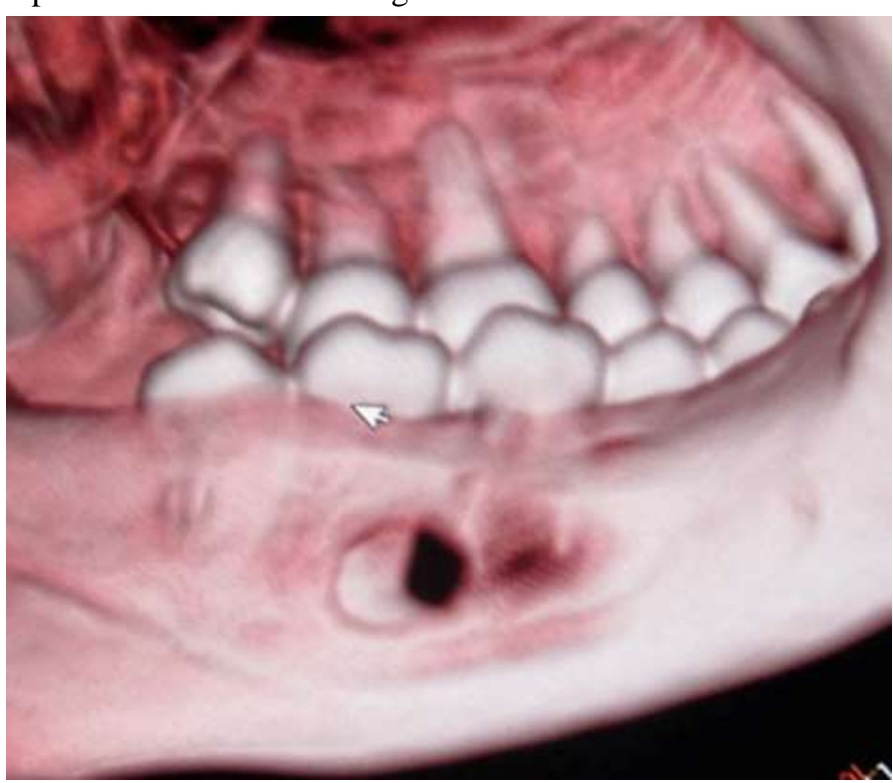

Fuente: Autores (2021).

Se propone tratamiento quirúrgico por biopsia excisional con extracción de los O.D 36, 37 y 38 e injerto óseo liofilizado con plasma rico en plaquetas. Se realiza procedimiento quirúrgico bajo anestesia general. Se aborda región 
paramandibular izquierda con colgajo mucoperióstico de espesor total, se observa perforación cortical y movilidad dental severa, se extraen los OD 36, 37 y 38 y se obtiene contenido líquido de aspecto serohemático. El epitelio de revestimiento intralesional y parcialmente adherido al primer molar se enuclea cuidadosamente para enviarlo a estudio anatomopatológico junto a los órganos dentarios. Posteriormente se lava con solución fisiológica $0.9 \%$ y se coloca injerto óseo liofilizado con vehículo de plasma rico en plaquetas, se afronta la herida quirúrgica con punto continuo anclado para lograr cierre hermético.

En el análisis macroscópico del espécimen remitido se observa en el O.D. 3.6 una prolongación cervical del esmalte que se extiende hacia la bifurcación vestibular (Figura 4).

Figura 4. Primer molar inferior izquierdo con proyección cervical del esmalte que se extiende hacia la furca. Se tiñen las raíces con eosina para destacar la interfaz amelocementaria.

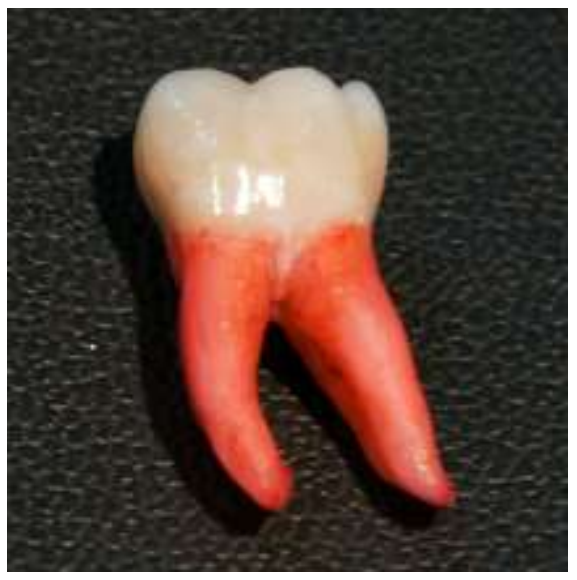

Fuente: Autores (2021).

En la descripción microscópica la muestra está constituida por gran cantidad de tejido conjuntivo hipercelular y colagenizado que forma la cápsula de la lesión, el epitelio se encuentra disperso debido a un abundante infiltrado crónico linfoplasmocitario en toda la extensión de la muestra. Adicionalmente presenta abundantes vasos sanguíneos llenos de eritrocitos, macrófagos en espuma (Figura 5), cristales de colesterol (Figura 6), cuerpos de Russell y cuerpos de Rushton. La correlación clínica, imagenológica e histopatológica determina compatibilidad con Quiste de la Bifurcación Bucal Mandibular.

Figura 5. Macrófagos en espuma. 40x (H/E).

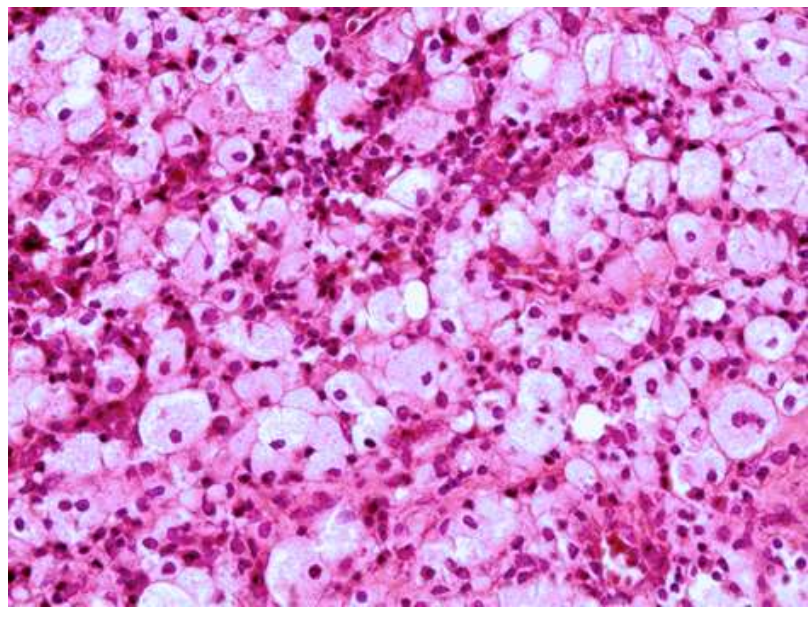

Fuente: Autores (2021).
Figura 6. Cristales de colesterol. 40x (H/E).

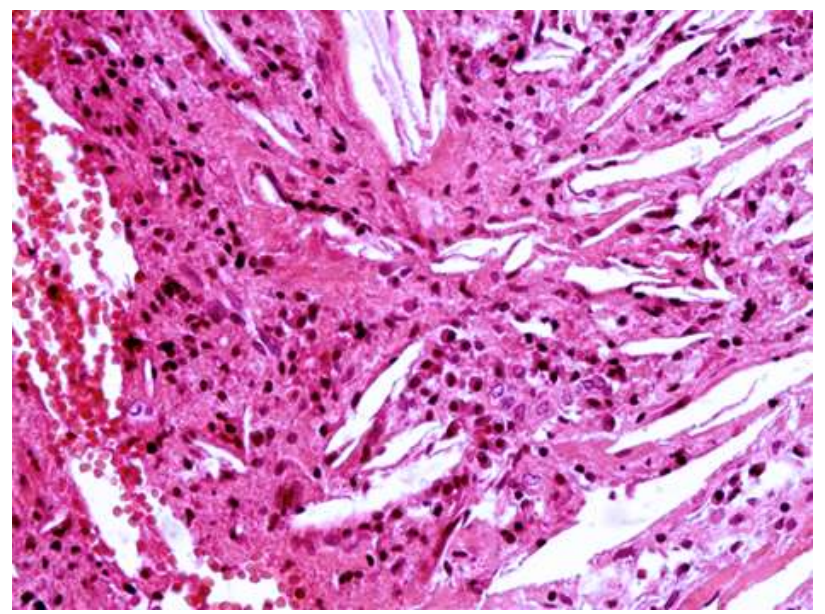

Fuente: Autores (2021). 


\section{Discusión}

El quiste de la bifurcación bucal mandibular, es un quiste odontogénico que presenta características clínicas y radiográficas específicas. Derindağ, Miloğlu, y Sümbüllü (2019) mencionan características específicas de edad, siendo más común en pacientes jóvenes, presentándose generalmente entre un rango de edad de 4 y 14 años; afectando más al sexo femenino en una relación 5:1 a 8:3 (Quintanilla, Amigo, Quintanilla, \& Hidalgo, 2018). Usualmente están asociados a la región vestibular del primer molar mandibular permanente y ocasionalmente el segundo molar, las superficies mesial y lingual raramente se encuentran involucradas (Derindağ, Miloğlu, \& Sümbüllü, 2019) (Martinez-Conde, Aguirre, \& Pindborg, 1995) (Corona-Rodriguez, Torres-Labardini, Velasco-Tizcareño, \& Mora-Rincones, 2011).

Krammer, Pindborg, y Shear (1992) sugieren que el QBBM es un quiste odontogénico poco común que comprende el $3.0 \%$ de todos los quistes de la mandíbula y el 3.7\% de los quistes odontogénicos, aunque su incidencia podría ser mayor ya que muchas de estas lesiones son diagnosticadas erróneamente, lo que concuerda con el estudio de Garcia, Bujaldón \& Rodriguez (2015). Usualmente se presenta de forma unilateral, sin embargo, se ha reportado una incidencia bilateral del $23.6 \%$ al 25\% de los casos, por lo cual se aconseja la evaluación de la pieza contralateral (Kramer, Pindborg, \& Shear, 1992) (Quintanilla, Amigo, Quintanilla, \& Hidalgo, 2018).

A pesar de las múltiples teorías Stoneman y Worth (1983) indican que la etiología del quiste de la bifurcación bucal permanece incierta y muy controvertida. El punto de común acuerdo es que durante la erupción dental al momento de perforar la mucosa oral la respuesta inflamatoria que se produce en el tejido conectivo estimula a los restos epiteliales del desarrollo dental produciendo la formación quística. Una explicación válida de porque se presenta en vestibular del primer molar es porque la cúspide mesiovestibular de este molar es la primera en perforar la mucosa oral (Zadik, Yitschaky, Neuman, \& Nitzan, 2011). Las características histológicas del QBBM son inespecíficas, e idénticas a la del quiste radicular (CoronaRodriguez, Torres-Labardini, Velasco-Tizcareño, \& Mora-Rincones, 2011) (Pompura, Sándor, \& Stoneman, 1997) (Stoneman \& Worth, 1983).

El diagnóstico debe realizarse mediante el análisis minucioso con correlación clínica, radiográfica e histopatológica. Pompura, Sándor, y Stoneman (1997) plantearon que esta lesión es autolimitada ya que es muy raro encontrarlas en adultos. Un argumento similar se utiliza en el quiste óseo simple por su baja incidencia en adultos y se considera resuelve espontáneamente inclusive en aquellos que rechazaron el tratamiento quirúrgico, pero aunque se considera un quiste de origen inflamatorio más que de desarrollo existe el contraste con lesiones que no resuelven espontáneamente y que con el tiempo incrementarán su tamaño si no se realiza la enucleación (Zadik, Yitschaky, Neuman, \& Nitzan, 2011). Tales, así como el quiste de la erupción y el folículo dental hiperplásico que pueden existir por décadas y expandirse si no son tratados (Derindağ, Miloğlu, \& Sümbüllü, 2019). Además, se han observado similitud con el quiste radicular lateral el cual se encuentra asociado a una pieza no vital, es así que una prueba eléctrica pulpar positiva puede ser un criterio diagnóstico del QBBM. (Derindağ, Miloğlu, \& Sümbüllü, 2019). Existen algunas similitudes con quistes del desarrollo como lo es el quiste dentígero, en particular ambas lesiones están asociadas a la corona del diente, siendo así que el quiste dentígero involucra la corona de un diente no erupcionado, por lo general terceros molares mandibulares, mientras que el QBBM es un quiste inflamatorio que surge en el sector vestibular de primeros y segundos molares vitales en proceso de erupción (Derindağ, Miloğlu, \& Sümbüllü, 2019).

El tratamiento del quiste de la bifurcación bucal mandibular ha evolucionado con el tiempo y ha sido motivo de controversia, Stoneman y Worth (1983) informaron el éxito del tratamiento mediante extracción del órgano dentario y curetaje de la lesión, así como con tratamiento endodóntico y curetaje. Pompura, Sándor, y Stoneman (1997) citado en el estudio de Deindağ, Miloğlu, y Sümbüllü, (2019) reportaron éxito después de la enucleación del quiste sin extracción del órgano dental. Al igual que Thikurrissy, Glazer, McNamara, y Tatakis, (2010) en procedimientos semejantes. Surge la propuesta más 
conservadora en el que la lesión se ha resuelto sin necesidad de cirugía. David Sàndor y Stoneman (1998), citado por Levarek, Wiltz, Kelsch y Kraut (2014) mencionan que es debido al sondaje inicial o a la irrigación diaria con solución salina en la bolsa vestibular lo que induce una "micromarzupialización” y permite la descompresión de la lesión con remisión espontánea sin cirugía.

Levarek, Wiltz, Kelsch y Kraut (2014) realizaron injerto óseo en tres casos después de la enucleación del quiste, proponiendo que esta mejora la regeneración ósea, proporcionando así estabilidad y permitiendo la reinserción de tejidos blandos. Pompura, Sándor, y Stoneman, (1997) reportaron que la cicatrización ósea se completa entre los 6 a 12 meses posteriores a la cirugía. Dagum y Escudero (2020) indican que la profundidad del saco periodontal del molar involucrado se restablece a los 12 meses, al igual que se completa su proceso de erupción. Las lesiones sintomáticas, infectadas, con expansión o perforación de corticales deben ser manejadas quirúrgicamente y si lo permite la lesión periodontal preservar los órganos dentarios (Zadik, Yitschaky, Neuman, \& Nitzan, 2011).

En la resolución de este caso en particular no fue considerado el tratamiento conservador por la movilidad grado III de los órganos dentarios relacionados, en base a la revisión de la literatura, y evolución favorable de la paciente con el injerto óseo sin complicaciones posteriores. Se reporta este caso para ayudar a futuras investigaciones sobre el tratamiento y el diagnostico diferencial del QBBM haciendo énfasis en la situación que la movilidad grado III no ha sido reportada como una característica de esta lesión quística.

\section{Conclusiones}

El quiste de la bifurcación bucal mandibular es una lesión odontogénica poco frecuente que afecta a el primer y segundo molar mandibular, presentándose con mayor frecuencia de manera unilateral. La correlación de los hallazgos clínicos, radiográficos e histológicos son un pilar fundamental para un correcto diagnóstico diferencial frente a entidades patológicas similares, estableciendo de esta manera un tratamiento adecuado. En este caso en particular la proyección del esmalte en la zona de la bifurcación fue un indicativo claro del QBBM, incidiendo en un paciente de 20 años que se encuentra fuera del rango de edad habitual de esta patología. El tratamiento de elección es la enucleación del quiste sin la extracción de la pieza dentaria asociada. Sin embargo, en este caso debido a la gran destrucción ósea y movilidad de las piezas involucradas se realizó la extracción de las mismas seguidas de un injerto óseo liofilizado para favorecer la cicatrización de los tejidos.

El análisis minucioso de las características tanto clínicas como histológicas, así como la aplicación de distintas herramientas diagnósticas, nos ofrecen una guía esencial para discernir entre distintas patologías del sistema estomatognático, por lo que se recomienda la recopilación de hallazgos y la colaboración multidisciplinaria, que guíen a un diagnóstico preciso en futuras investigaciones.

\section{Referencias}

Ackermann, G., Cohen, M. A., \& Altini, M. (1987). The paradental cyst: a clinicopathologic study of 50 cases. Oral Surgery, Oral Medicine, Oral Pathology, 64(3), 308-312.

Bautista, C., Milhan, N., Ankha, M., do Prado, R., Cavalcante, A., de Castro, S., \& Anbinder, A. (2019). Bilateral mandibular buccal bifurcation cyst: a case report emphasizing the role of imaging examination in the diagnosis. Autopsy \& case reports, 9(2).

Chrcanovic, B. R., Reis, B., \& Freire-Maia, B. (2011). Paradental (mandibular inflammatory buccal) cyst. Head and neck pathology, 5(2), 159-164.

Corona-Rodriguez, J., Torres-Labardini, R., Velasco-Tizcareño, M., \& Mora-Rincones, O. (2011). Quiste de bifurcación bucal bilateral: reporte de un caso y revisión de la literatura. Revista de cirugía oral y maxilofacial, 69(6), 1694-1696.

Craig, G. T., \& GT, C. (1976). The paradental cyst. A specific inflammatory odontogenic cyst. British Dental Journal, 9-14.

Dagum , H., \& Escudero, F. (2020). Quiste bucal mandibular infectado bilateral: reporte de caso estudiado con CBCT. Rev. Ateneo Argent, 9-12. 
Research, Society and Development, v. 10, n. 5, e36010515201, 2021

(CC BY 4.0) | ISSN 2525-3409 | DOI: http://dx.doi.org/10.33448/rsd-v10i5.15201

David, L., Sàndor, G., \& Stoneman, D. (1998). The buccal bifurcation cyst: is non-surgical treatment an option?. Journal-Canadian Dental Association, 64, $712-717$.

Derindağ, G., Miloğlu, Ö., \& Sümbüllü, M. (2019). Derindağ, G, MBuccal bifurcation cyst (paradental cyst) defined by ultrasonography and cone-beam computed tomography. Oral radiology, 35(3), 315-320.

García-Rubio , A., Bujaldón-Daza, A., \& Rodríguez-Archilla, A. (2015). Lesiones periapicales: diagnóstico y tratamiento. Avances en Odontoestomatología, $31(1), 31-42$.

Hernández, R., Fernández, C., \& Baptista, P. (2014). Metodoligía de la investigación. McGraw Hill.

Hofrath, H. (1930). Uber das Vorkommen von Talgdrusen in der Wandung einer Zahncyste, zugleich ein Beitrag zur Pathogenese der Kiefer-Zahncysten. Dtsch Monatsschr Zahnheilkd, 48, 65-76.

Kramer, I. R., Pindborg, J. J., \& Shear, M. (1992). The WHO histological typing of odontogenic tumours. A commentary on the second edition. Cancer, 70(12), 2988-2994.

Levarek, R., Wiltz, M., Kelsch, R., \& Kraut, R. (2014). Manejo quirúrgico del quiste de bifurcación bucal: injerto óseo como tratamiento adjunto a la enucleación y legrado. Revista de Cirugía Oral y Maxilofacial, 72(10), 1966-1973.

Main, D. M. (1970). Epithelial jaw cysts: a clinicopathological reappraisal. British Journal of Oral Surgery, 8(2), 114-125.

Martinez-Conde, R., Aguirre, J., \& Pindborg. (1995). Paradental cyst of the second molar: report of a bilateral case. Journal of oral and maxillofacial surgery, $53(10), 1212-1214$.

Neville, B. W., Damm, D. D., Allen, C. M., \& Chi, A. C. (2015). Oral and maxillofacial pathology (4a ed.). Elsevier Health Sciences.

Philipsen, H. P., Reichart, P. A., Ogawa, I., Suei, Y., \& Takata, T. (2004). The inflammatory paradental cyst: a critical review of 342 cases from a literature survey, including 17 new cases from the author's files. Journal of oral pathology \& medicine, 33(3), 147- 155.

Pompura, J., Sándor, G., \& Stoneman, D. (1997). The buccal bifurcation cyst: a prospective study of treatment outcomes in 44 sites. Oral Surgery, Oral Medicine, Oral Pathology, Oral Radiology, and Endodontology, 83(2), 215-221.

Quintanilla, M., Amigo, S., Quintanilla, F., \& Hidalgo, A. (2018). Quiste bucal mandibular infectado bilateral en segundos molares permanentes: reporte de un caso. Avances en Odontoestomatología, 34(1), 19-24.

Shear, M., \& Speight, P. (2008). Cysts of the oral and maxillofacial regions (4a ed.). Blackwell-Munksgaard.

Stoneman, D., \& Worth, H. (1983). The mandibular infected buccal cyst--molar area. Dental radiography and photography, 56(1), 1-14.

Thikkurissy, S., Glazer, K., McNamara, K., \& Tatakis, D. (2010). Quiste de bifurcación bucal en un niño de 7 años: manejo quirúrgico y seguimiento a los 14 meses. Revista de periodoncia, 81(3), 442-446.

Zadik, Y., Yitschaky, O., Neuman, T., \& Nitzan, D. (2011). Sobre la naturaleza de autorresolución del quiste de bifurcación bucal. Revista de cirugía oral y maxilofacial, 69(7), e282. 